\title{
Influence of Courtyard Ventilation on Thermal Performance of Office Building in Hot-Humid Climate: A Case Study
}

\author{
Esra'a Sh. Abbaas ${ }^{1 *}$, Ala'eddin A. Saif ${ }^{2}$, MAC Munaaim $^{1}$, and Md. Azree Othuman Mydin ${ }^{2}$ \\ ${ }^{1}$ School of Environmental Engineering, Universiti Malaysia Perlis, 02600 Arau, Perlis, Malaysia \\ ${ }^{2}$ School of Microelectronic Engineering, Universiti Malaysia Perlis, 02600 Arau, Perlis, Malaysia \\ ${ }^{3}$ School of Housing, Building and Planning, Universiti Sains Malaysia, Pulau Pinang. Malaysia
}

\begin{abstract}
The influence of courtyard on the thermal performance of Development Department office building in University Malaysia Perlis (UniMAP, Pauh Putra campus) is investigated through simulation study for the effect of ventilation on indoor air temperature and relative humidity of the building. The study is carried out using EnergyPlus simulator interface within OpenStudio and SketchUp plug in software to measure both of air temperature and relative humidity hourly on 21 April 2017 as a design day. The results show that the ventilation through the windows facing the courtyard has sufficient effect on reducing the air temperature compared to the ventilation through external windows since natural ventilation is highly effective on driving the indoor warm air out to courtyard. In addition, the relative humidity is reduced due to ventilation since the courtyard has high ability to remove or dilute indoor airborne pollutants coming from indoor sources. This indicates that the presence of courtyard is highly influential on thermal performance of the building.
\end{abstract}

\section{Introduction}

The increment in human activities and industrial revolution leads to sharp changes in the ecosystem and accordingly in climate due to the incredibly increase in earth temperature, which in turn causes global warming phenomena. Building sector consumes about $40 \%$ of total energy in the world, moreover, the office type of buildings required $50 \%$ of total energy consumption of non-residential buildings since many persons are existed in limited zone in the same time [1]. The continued increases in global warming and energy consumption required to apply sustainable concepts in order to reduce their effect in daily life. Applying sustainable concepts in buildings considered one of main approaches to maintain energy consumption [2]. Many solutions have been proposed to improve the thermal comfort of buildings in hot humid areas. Among of them, introducing courtyard to buildings enhances the thermal performance for the building's interior due to its impact on the passive cooling [3].

There are many reports reveal that using internal courtyard helps the air to flow within the interior spaces of the building and it also helps getting rid of the hot air inside the building [4].

* Corresponding author:esraabbas91@gmail.com 
The courtyard building architecture form enhances the thermal performance of the building by natural ventilation due to shade creating [5]. However, constructing appropriate openings in both sides of the adjacent spaces for courtyard can enhance the natural ventilation, which in turn improves the thermal performance [6-7].

[8] studied the effect of natural ventilation in office building in hot-humid climate and reported that the thermal condition of the spaces increases, and the occupants feel comfort when the wind speed higher than $0.1 \mathrm{~m} / \mathrm{s}$, so to get better results, one has to use the natural ventilation when the outdoor temperature is lower than indoor temperature. Courtyard had been used as a part of buildings in different countries located in hot-humid areas such as China and India [9], however, it still not common in Malaysia. In this work, a simulation study for the effect of natural ventilation due to internal courtyard in an existence office building in Malaysia on its thermal performance.

\section{Case Study Descriptions}

In this work, Development Department building in University Malaysia Perlis (UniMAP) that is located in Pauh Putra campus has been taken as a case study. It has central rectangular courtyard with a dimension of $14.9 \times 26.1 \mathrm{~m}^{2}$ and all offices and meeting rooms surrounding it. Fig. 1 shows the two dimensional AutoCAD ground floor plan drawing for the building, which has been divided into four zones, i.e. North, South, East and West zone with respected to the central courtyard with an area of $333.18 \mathrm{~m}^{2}, 373.93 \mathrm{~m}^{2}, 338.86 \mathrm{~m}^{2}$ and $415.48 \mathrm{~m}^{2}$, respectively. Regarding to the weather conditions, Malaysia is considered a high humidity region and the humidity slightly varies along the country, the average value of humidity is within the range of $70 \%-90 \%$. On the other hand, the average temperature is within the range of $29{ }^{\circ} \mathrm{C}$ to $34{ }^{\circ} \mathrm{C}$ [5].

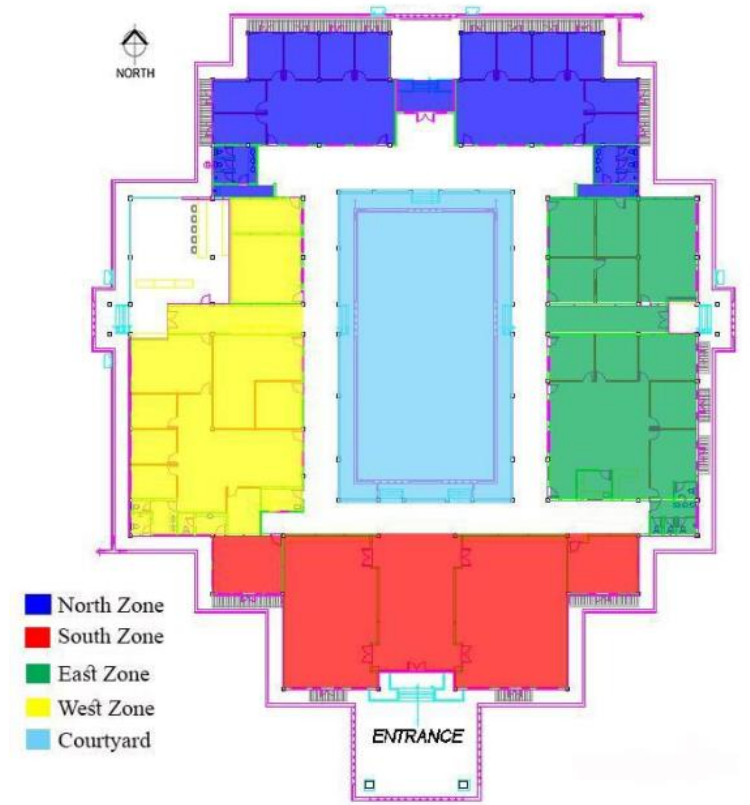

Fig. 1. 2D AutoCAD floor ground plan drawing for Development Department building in UniMAP with the zones. 


\section{Methodology}

The Development Department building has rectangular courtyard with offices surrounding it which are set as four thermal zones as shown in Fig. 1. The two dimensional plan for the building is drawn using AutoCAD, then the three dimensional model for the building has been built using SketchUp with OpenStudio software. The model construction is set based on the materials for the exiting building, and then the internal heat loads for building including people, lights and electric equipment are scheduled, moreover, the ventilation system is activated. Before the model is simulated using EnergyPlus simulator, the climate file for Malaysia that was obtained from US DOE website in EPW format was imported to the software in order to set all environmental conditions, then the design day from DDY file was also imported, where 21 April 2017 is selected to be the design day in this study. After that, the physical output quantities, particularly the air temperature and relative humidity are specified and set to be measured hourly.

\section{Results and discussions}

Fig. 2 shows the hourly changing in indoor air temperature for the adjacent zones to the courtyard on 21 April 2017 design day with and without ventilation. The results show that for all cases opening the windows after midnight until early morning, particularly, from 12:00 am to 8:00 am has unnoticeable effect on the interior air temperature since the outdoor air temperature is very close to the indoor air temperature. However, starting from 9:00 am until 11:00 pm, the ventilation through windows is more effective. In all cases the nature ventilation through windows reduces the air temperature for the interior zones, indicating that the thermal performance of the building is enhanced. From Fig. 2, it can be observed that the ventilation through the external windows slightly reduces the air temperature for the interior spaces of the building compared to the case where all windows are closed. For instance, the maximum air temperature difference between the case of ventilation through external windows and the case of no ventilation for the east zone is recorded at $10: 00$ am and it is $0.49{ }^{\circ} \mathrm{C}$.

A lower interior air temperature has been obtained due to ventilation through the windows that are facing the courtyard compared to the case of ventilation through external windows. For example, the maximum air temperature difference between the case of ventilation through the windows on courtyard and the case of no ventilation for the east zone is also recorded at 10:00 am and it is $1.56{ }^{\circ} \mathrm{C}$, which is triple the air temperature difference obtained in case of external windows ventilation. The better performance of ventilation through windows on courtyard can be explained as follows: courtyard acts as an air tube that let out the internal air into sky due to the deference of air density between indoor and outdoor and this mechanism is called the stack driven ventilation [10].

The lowest indoor air temperature is obtained for the case when all windows of the building are opened. For instance, the maximum air temperature difference between the case of ventilation through all windows and the case of no ventilation for the east zone is also recorded at 10:00 am which is $1.71{ }^{\circ} \mathrm{C}$. The large air temperature difference for ventilation through all windows is due to the existence of opposite sides window, which creates path for the air through the building, hence, better natural ventilation circulation that minimize indoor air temperature and enhancing thermal performance of the building. This ventilation mechanism is called cross driven ventilation [10].

It is interesting to mention here that ventilation through the windows facing the courtyard has very close results to the cross ventilation case. This implies that the presence of courtyard is highly effective on thermal performance of the building resultant due to nature ventilation. In addition, it is important to clarify here that due to non-presence of windows on the courtyard for 
south zone in the building, no stack and cross ventilation values for the indoor air temperature are recorded in this zone.

[11] studied the performance of courtyard of a single story building in hot-humid area and they found that creating openings for the building on the courtyard effects on airflow, hence, improves of the thermal behavior of the interior zone, which is in line with our results. Another study by [10] reported the effect of natural ventilation strategies on thermal behavior of existing school building with a courtyard in Italy and they concluded that all ventilation strategies enhance the thermal comfort for the indoor zones of building. Additionally, the cross ventilation gives better results compared to stacks driven ventilation strategy which is similar to our findings for hot-humid climate.

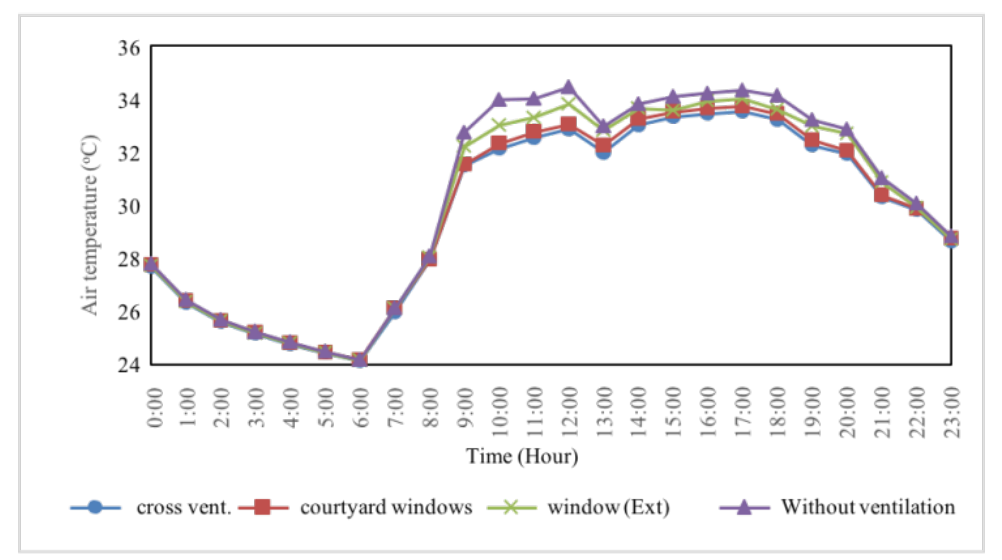

(a)

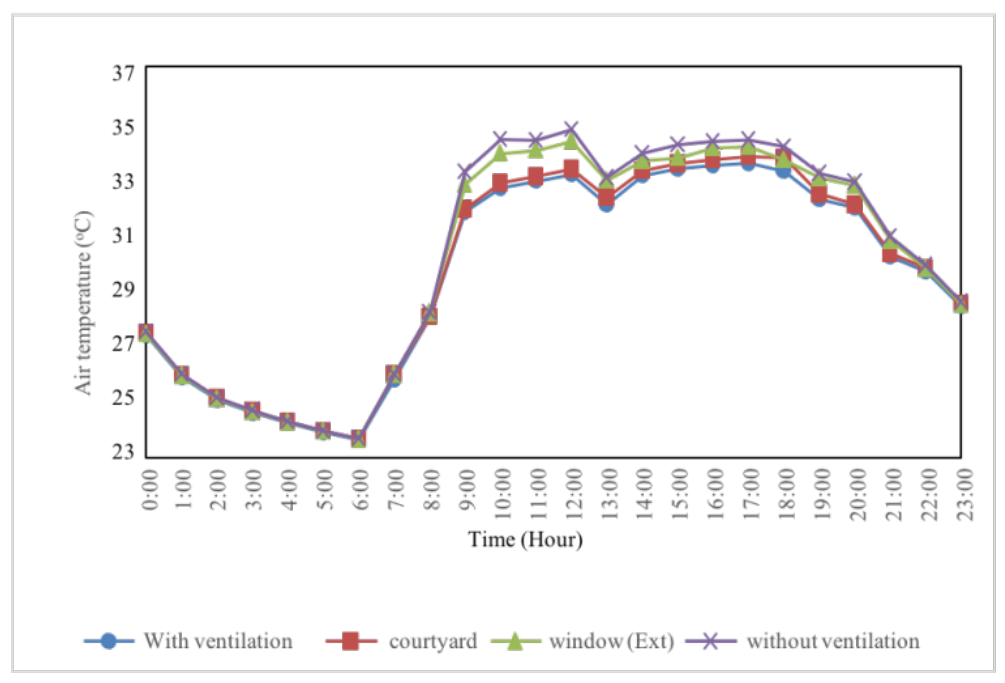

(b) 


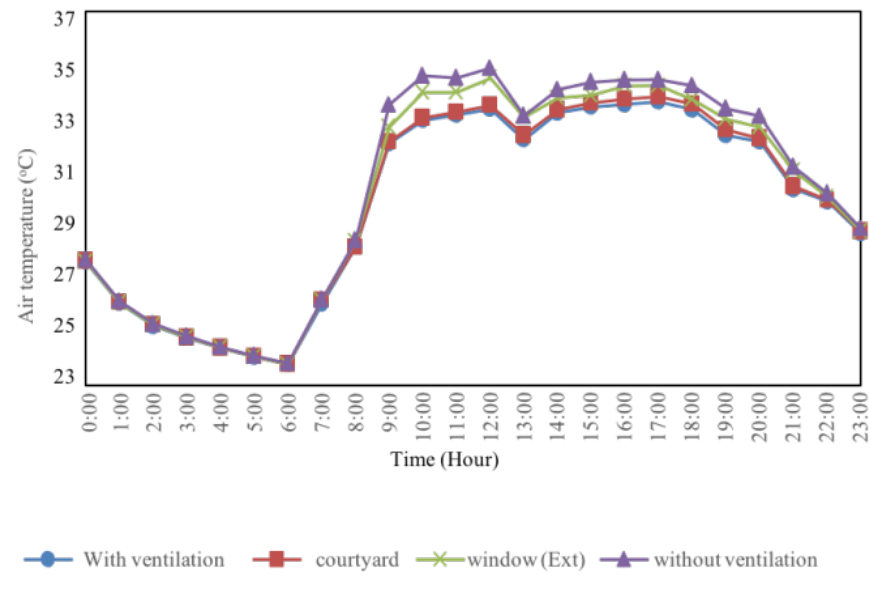

(c)

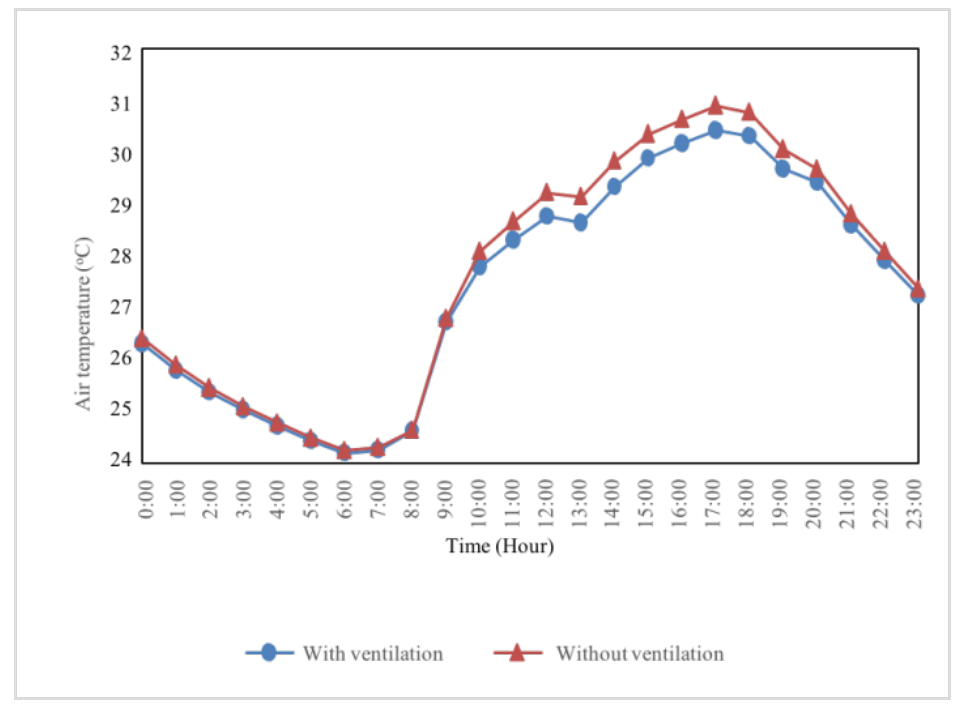

(d)

Fig. 2. Hourly indoor air temperature variation for Development Department building (Jabatan Pembangunan) at University Malaysia Perlis (UniMAP, Pauh Putra campus) on 21 April 2017 for: (a) North façade, (b) East façade, (c) West façade and (d) South façade.

Fig. 3 illustrates the variation of indoor relative humidity for the zones surrounded to the courtyard on 21 April 2017 for the cases with and without ventilation. The results show that the relative humidity for the building is quite high and reaches to $100 \%$ at most of the measurement time for the case without ventilation. This is attributed to presence of the electrical equipment loads and light loads in addition the occupants who are using the building as set earlier. The existence of all these type of loads, especially human factor, increases the amount of moisture for the indoor air that in turn increases the relative humidity.

It is also observed that the relative humidity for the case without ventilation of the north zone during the period between 2:00 am and 7:00 am has lower values compared to the other zones 
within this duration of time. This is due the higher air temperature measured for this zone compared to the other zones at these times as shown in Figure 2, which it is inversely proportional to the relative humidity [12].

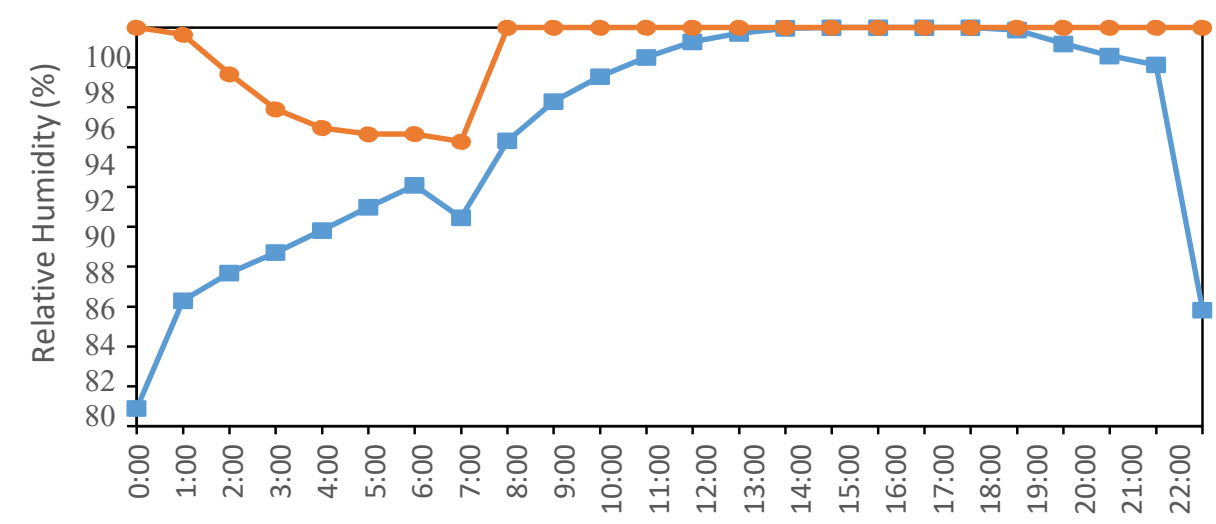

Time (hour)

$\longrightarrow$ with ventilation $\longrightarrow$ without ventilation

(a)

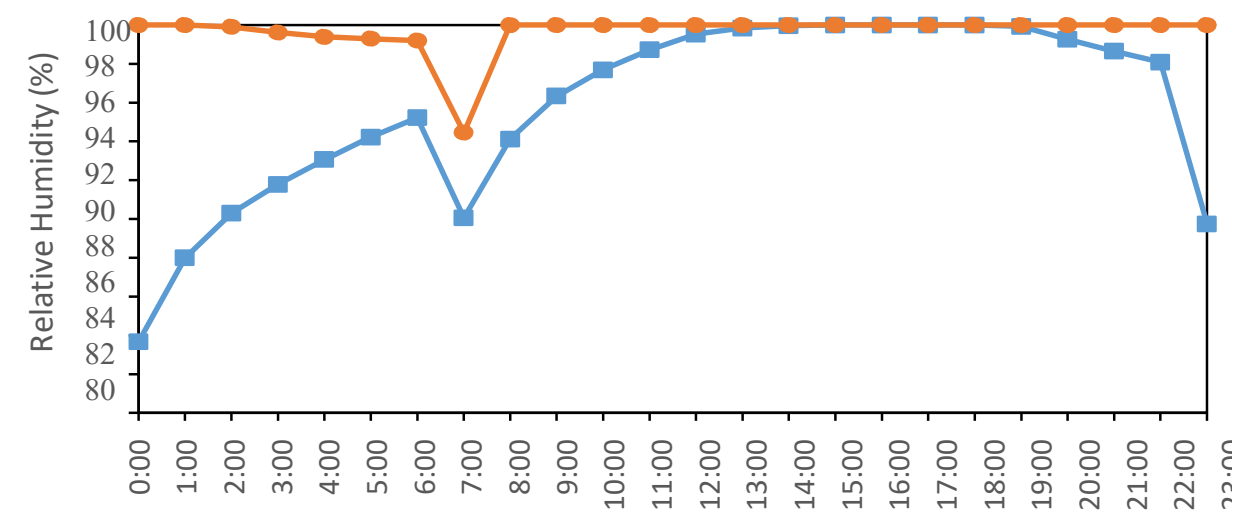

Time (hour)

$\longrightarrow$ with ventilation $\longrightarrow$ without ventilation

(b) 


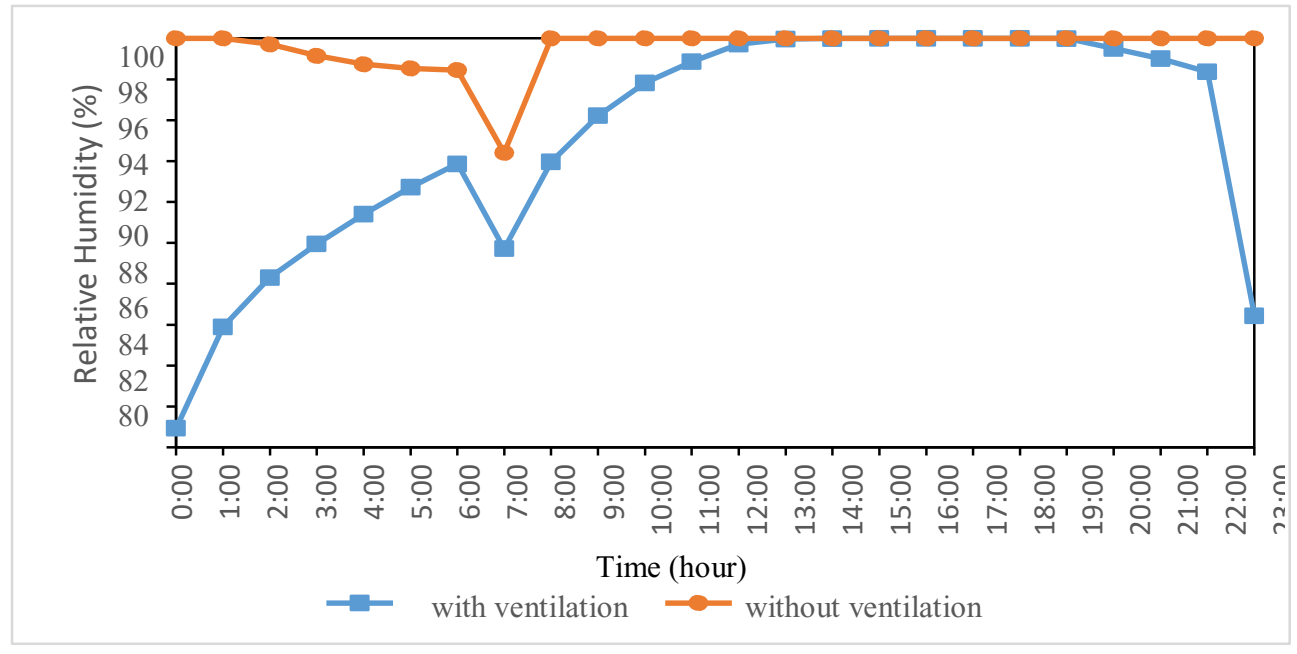

(c)

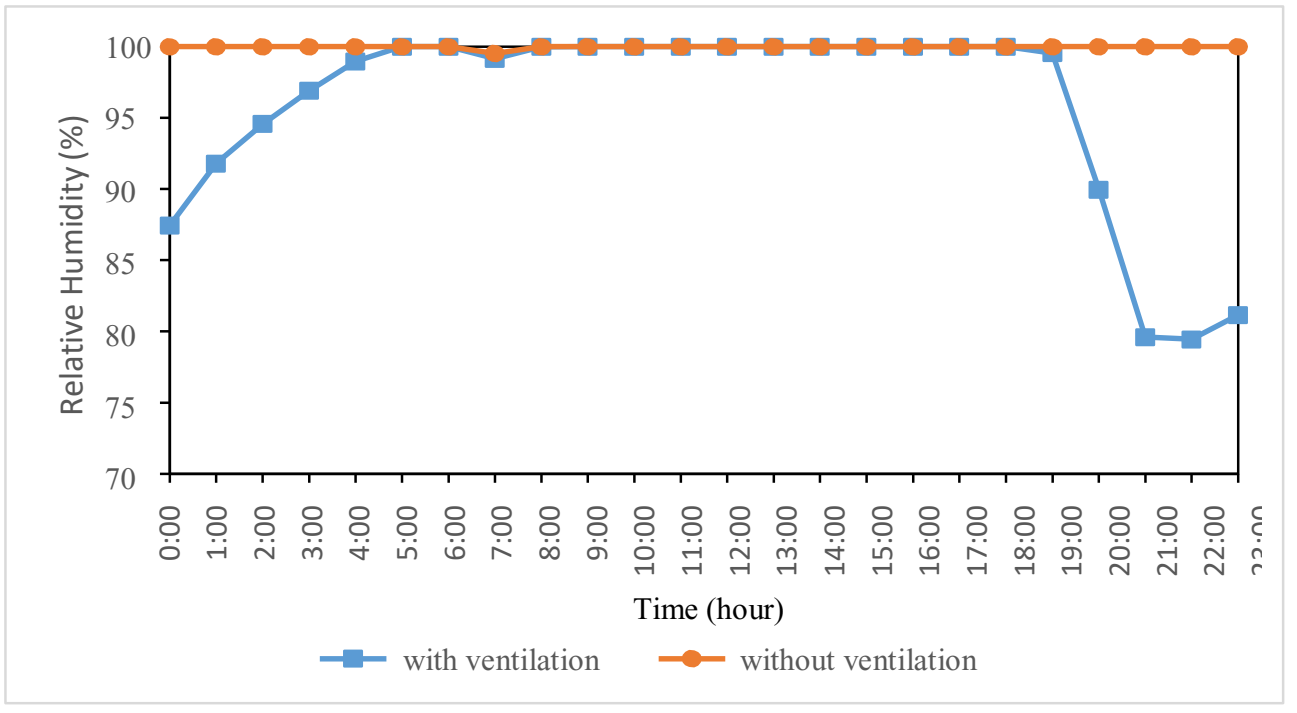

(d)

Fig. 3. Hourly indoor relative humidity variation for Development Department building (Jabatan Pembangunan) at University Malaysia Perlis (UniMAP, Pauh Putra campus) on 21 April 2017for: (a) North façade, (b) East façade, (c) West façade and (d) South façade.

In all zones, the nature ventilation through windows reduces the relative humidity for the interior zones, indicating that the thermal comfort of the building is enhanced. For instance, the relative humidity for the north zone drop from $100 \%$ to $81 \%$ at $12: 00$ am due to the natural ventilation then it increases gradually with the time and reaches to $100 \%$ again at 3:00 pm. The drop in humidity values at night. Hence, it flows into the adjacent interior areas and drives the warm air out of these areas, which in turn intends to remove or dilute indoor airborne pollutants 
concentration that are coming from indoor sources. This reduces the level of contaminants and improves indoor air quality [13]. Same drop in relative humidity values is also noticed after 7:00 pm for all zones.

It is important to mention here that in this experiment stack driven ventilation is considered for north, east and west zones since its high efficiency compared to the other ventilation types as discussed in Fig. 2, while ventilation through external windows for south zone is considered since it is the only ventilation possible for this zone. Therefore, higher drop difference in relative humidity is observed for north, east and west zones compared to the one obtained for the south zone as illustrated in Fig. 3(d).

\section{Conclusions}

This paper introduces a simulation study for the influence of natural ventilation due to the central courtyard at Development Department building in University Malaysia Perlis (UniMAP, Pauh Putra campus) using EnergyPlus software. The interior air temperature and relative humidity for the building have been measured hourly for the design day of 21 April 2017. It has been found that the presence of courtyard is highly effective on reducing both of indoor air temperature and humidity due to the natural ventilation through the windows that are facing it. Where ventilation through windows allows the warm indoor air to be released at the adjacent zones at the courtyard, which in other way reduces the air temperature. Additionally, it helps to remove or dilute indoor air pollutants that are originate from indoor sources.

\section{References}

1. L. Perez-Lombard, J. Ortiz, C.H. Pout, Energy. Build. 40, 3 (2008).

2. S. Cho, N. Mohammadazadeh, IBPSA (2013).

3. D. H. Ch. Toe, Doctoral Dissertation, (2013).

4. N. Moosavi, N. Mahyuddin, N. Abd Ghafar, M. A. Ismail, Ren. Sus. Energy. Rev. 34 (2014).

5. M. A. Zakaria, and L.H.Ismail, IConCEES (2011).

6. N. Sadafi, E. Salleh, L. Ch. Haw, Z. Jaafer, J. App. Sci. 8, 15 (2008).

7. T. Tabesh, B. Sertyesilisik, Amer. Trans. Eng. App. Sci. 3, 2 (2014)

8. R. Daghigh, K. Sopian, J. Mostagh, Eur. J. Sci. Res. 26, 2 (2009).

9. C. Chan, Y. Xiong, Arch. Conf. Proc. Pres. 62 (2005).

10. L. Lion, A. Belleri, R. Lollini, D. Zardi, L. Giovannini, 33rd AIVC- 2nd TightVent. Con. (2012).

11. Rajapaksha, H. Nagai, M. Okumiya, Ren. Energy. 28 (2003).

12. H. Djamila, Ch. Chu, S. Kumaresan, J. Build. Const. Plan. Res. 2 (2014).

13. K. Ponsoni, M. S. G. Raddi, Braz. Arch. Biol. Tech. 53, 1 (2010). 